DOI: https://doi.org/10.24127/ajpm.v10i2.3558

\title{
PERBEDAAN HASIL BELAJAR MATEMATIKA MATERI SPLDV PADA SISWA SMP DI KOTA AMBON
}

\author{
Anderson Leonardo Palinussa ${ }^{1 *}$, Hanisa Tamalene ${ }^{2}$ \\ ${ }^{1 *}, 2$ Pendidikan Matematika, Universitas Pattimura, Ambon, Indonesia \\ *Corresponding author \\ E-mail: $\quad \frac{\text { palinussaandersonl@gmail.com }}{{ }^{*} \text { tamalene80nissa@gmail.com }}{ }^{2)}$
}

Received 12 February 2021; Received in revised form 14 June 2021; Accepted 06 July 2021

\begin{abstract}
Abstrak
Penelitian ini bertujuan untuk mengetahui perbedaan hasil belajar matematika siswa pada materi sistem persamaan linear dua variabel (SPLDV) dengan menggunakan model pembelajaran Realistic Mathematic Education (RME), Problem Based Learnig (PBL) dan konvensional. Populasi pada penelitian ini sebanyak 6 kelas dengan sampel adalah 3 kelas yang dipilih menggunakan teknik purposive sampling. Data yang diperoleh kemudian dianalisis menggunakan $\mathrm{N}$-Gain untuk mengetahui peningkatan hasil belajar, selanjutnya digunakan uji analisis variansi satu arah (One Way ANOVA) untuk menguji perbedaan peningkatan hasil belajar. Berdasarkan pada hasil analisis data maka diperoleh kesimpulan, 1) terdapat peningkatan hasil belajar matematika siswa dengan menggunakan model pembelajaran RME, PBL dan Konvensional, 2) terdapat perbedaan peningkatan hasil belajar matematika siswa dengan menggunakan model pembelajaran RME, PBL dan konvensional. Hal ini terlihat pada nilai sig kelas RME terhadap kelas konvensional yaitu $0,00<0,05$ (nilai $\alpha$ ), sehingga terdapat perbedaan peningkatan hasil belajar antara kelas RME dan kelas konvensional. Selanjutnya nilai sig RME terhadap PBL yaitu $0,012<0,05$ (nilai $\alpha$ ), sehingga terdapat perbedaan peningkatan hasil belajar antara kelas RME dan kelas PBL. Sedangkan nilai Sig kelas PBL terhadap kelas konvensional yaitu $0,003<0,05$ (nilai $\alpha$ ), sehingga terdapat perbedaan peningkatan hasil belajar antara model pembelajaran PBL dan model pembelajaran konvensional. Dengan demikian RME dapat direkomendasikan dalam meningkatkan hasil belajar matematika siswa
\end{abstract}

Kata kunci: Hasil belajar; konvensional; PBl; RME.

\begin{abstract}
This study aims to determine the differences in student mathematics learning outcomes on Two-variable linear equations (SPLDV) material using the Realistic Mathematic Education (RME), Problem Based Learning (PBL) and conventional learning models in class VIII students of SMP Negeri 15 Ambon. The population in this study were 6 classes with a sample of 3 classes which were selected using purposive sampling technique. The three classes selected were class VIII3, VIII5 and VIII6. Class VIII3 uses the PBL learning model, class VIII5 uses the conventional learning model and class VIII6 uses the RME learning model. The data obtained were then analyzed using $N$-Gain to determine the increase in learning outcomes, then the one-way analysis of variance test (One Way ANOVA) was used to test differences in the improvement of learning outcomes. Based on the results of data analysis, the conclusions are obtained, 1) there is an increase in student mathematics learning outcomes using the RME, PBL and conventional learning models, 2) there are differences in the improvement of students' mathematics learning outcomes using the RME, PBL and conventional learning models. This can be seen in the sig value of the RME class against the conventional class, namely $0.00<0.05$ ( $\alpha$ value), so that there is a difference in the improvement of learning outcomes between the RME class and the conventional class. Furthermore, the RME sig value for PBL is $0.012<0.05$ ( $\alpha$ value), so there is a difference in the improvement of learning outcomes between the RME class and the PBL class. While the Sig value of PBL class to conventional class is $0.003<0.05$ ( $\alpha$ value), so there is a difference in the improvement of learning outcomes between PBL learning models and conventional learning models.
\end{abstract}

Keywords: Conventional; learning outcomes; PBL; RME.

This is an open access article under the Creative Commons Attribution 4.0 International License 
DOI: https://doi.org/10.24127/ajpm.v10i2.3558

\section{PENDAHULUAN}

Kemampuan matematika siswa di Indonesia masih cukup rendah. Hal ini terlihat pada data PISA 2018 (OECD, 2019) terkait kemampuan matematika siswa di Indonesia menempati posisi 72, menurun dari tahun 2015 yang berada pada posisi 64 (Shin et al., 2018). Hal ini juga memiliki kaitan yang sangat erat dengan proses pembelajaran matematika di sekolah, karena dari proses pembelajaran matematika di sekolah harus memenuhi tujuan pembelajaran yaitu peningkatan kemampuan matematis siswa (Rylands \& Shearman, 2018).

Pembelajaran matematika di sekolah harus mendapat perhatian khusus dari para guru matematika (Zwart et al., 2017). Hal ini dimaksudkan agar guru dapat menggunakan model yang berbeda namun harus disesuaikan dengan materi serta kondisi dan situasi di dalam kelas (Wu et al., 2020). Pembelajaran dengan menggunakan model yang tepat dapat membantu siswa untuk menerima materi (Kolovou \& Kim, 2020). Selain itu pembelajaran juga harus lebih dipusatkan kepada siswa agar dapat meningkatkan aktivitas belajar dan menemukan sendiri konsep dalam matematika (Eronen \& Kärnä, 2018). Perlu adanya inovasi pembelajaran matematika pada siswa yang memberikan kesempatan kepada siswa untuk dapat meningkatkan aktivitas belajar (King et al., 2017).

Bertolak dari pembelajaran yang bersifat realistik serta pemecahan masalah, maka ditemukan bahwa siswa sering mengalami kesulitan dalam menyelesaikan soal-soal latihan dan tugas yang diberikan oleh guru. Hal ini terbukti dari hasil matematik siswa di Maluku masih sangat rendah yaitu 35.27 (Ratumanan, 2016). Salah satu penyebab hasil belajar matematika rendah adalah banyak siswa tidak memahami konsep matematika yang diajarkan oleh guru dan kemampuan matematika sejak di tingkat bawah tidak ditanamkan secara baik, sehingga terbawah sampai tingkatan yang paling atas (Harahap \& Surya, 2017).

Menyikapi hal ini, guru harus pandai menggunakan strategi atau model dengan bijaksana serta tidak sembarangan yang dapat merugikan siswa. Dimana pemilihan metode yang digunakan berorientasi untuk meningkatkan prestasi dan minat siswa dalam matematika (Mbacho \& Changeiywo, 2013). Model pembelajaran yang membantu siswa lebih aktif dalam belajar serta menggunakan model pembelajaran yang dapat mendorong siswa dalam mengkonstruksikan objek-objek yang realistik menjadi objek yang abstrak yang berbasis pada masalah (Revina \& Leung, 2019). Salah satu model pembelajaran yang dapat digunakan adalah model pembelajaran Realistic Mathematic Education (RME) (Laurens et al., 2018). RME menekankan pentingnya konteks nyata yang dikenal siswa dan proses konstruksi pengetahuan matematika oleh siswa sendiri (Sitorus \& Masrayati, 2016). Masalah konteks nyata dijadikan titik pangkal (starting point) dalam pembelajaran matematika. Konstruksi pengetahuan matematika oleh siswa berlangsung dalam proses yang oleh Freudenthal dinamakan penemuan kembali (guided reinvention). Penemuan kembali merupakan salah satu prinsip utama dalam RME (Sumirattana et al., 2017).

Selain model pembelajaran yang bersifat realistik, pembelajaran juga dapat menggunakan model yang menitik beratkan pada masalah yang 
harus dipecahkan oleh siswa. Salah satu model yang dapat digunakan yakni model Problem Based Learing (PBL) (Seibert, 2021). PBL merupakan salah satu model pembelajaran yang dianggap paling mujarab dalam menolong siswa dan memberikan kondisi belajar aktif serta mengarahkan untuk bersama-sama memecahkan suatu masalah (Perusso \& Baaken, 2020). PBL menggunakan masalah dunia nyata sebagai suatu konteks belajar bagi siswa tentang cara berpikir kritis dan termapil dalam pemecahan masalah matematis ( $\mathrm{Li}$ et al., 2020). PBL lebih mengedepankan pembelajaran yang dimulai dari masalah. Dimana siswa belajar suatu konsep dan prinsip sekaligus memecahkan masalah. Dengan demikian, terdapat sekurang-kurangnya dua hasil belajar yang diperoleh siswa, yakni jawaban dari masalah serta cara untuk memecahkan masalah tersebut (Batlolona et al., 2020). Selain itu dengan PBL dapat mengarah pada hasil belajar yang lebih postif dan mengembangkan kebiasaan kemandirian dalam belajar dan mendisiplinkan diri untuk belajar (Yew \& Goh, 2016).

Komparasi penelitian dalam pembelajaran mematika dengan menggunakan RME dan PBL dengan konvensional pada materi SPLDV masih jarang di eksplorasi. Sekalipun ada, tapi masih terpisah atau dengan variabel yang berbeda. Hal ini dapat terlihat dari hasil penelitian Widyatiningtyas et al., (2015) menjelaskan bahwa PBL dapat meningkatkan keterampilan berpikir kritis siswa yang ditinjau dari kemampuan awal matematik siswa. Selain itu penelitian dari Wardono et al., (2016) menunjukkan bahwa kemampuan literasi matematika siswa pada soal-soal PISA dengan menggunakan model PBL dengan pendekatanan RME berbantuan Elearnig Edmodo lebih tinggi bila bandingkan dengan pedekatan ekspositori.

Berdasarkan pada pemaparan di atas, maka dilakukan penelitian dan eksplorasi lebih dalam terkait perbedaan hasil belajar matematika siswa pada materi SPLDV dengan model pembelajaran yang berbeda. Adapun tujuan dari penelitian ini untuk mengetahui perbedaan hasil belajar matematika siswa pada materi SPLDV dengan menggunakan model pembelajaran RME, PBL dan konvensional siswa.

\section{METODE PENELITIAN}

Desain yang digunakan dalam penelitian ini adalah eksperimen dengan kelompok kontrol pretest dan posttest. Desain penelitian dapat ditunjukan seperti di bawah ini.

$\begin{array}{lll}\text { A: O } & \text { X1 } & \text { O } \\ \text { A: O } & \text { X2 } & \text { O } \\ \text { A: O } & \text { X3 } & \text { O }\end{array}$

Keterangan

$$
\begin{gathered}
\mathrm{A}: \text { Sampel } \\
\mathrm{O}: \text { Tes (Pretest } \text { dan posttest) } \\
\mathrm{X} 1 \quad: \text { Pembelajaran konvensional. } \\
\mathrm{X} 2 \quad: \text { Pembelajaran dengan RME } \\
\mathrm{X} 3 \quad: \text { Pembelajaran dengan PBL }
\end{gathered}
$$

Penelitian ini dilaksanakan di kelas VIII SMP Negeri 15 Ambon. Sampel penelitian sebanyak 56 siswa diambil dengan menggunakan teknik Cluster Sampling meliputi kelas $\mathrm{VIII}_{3}$ menggunakan model pembelajaran PBL, $\mathrm{VIII}_{5}$ menggunakan model pembelajar konvensional dan $\mathrm{VIII}_{6}$ menggunakan model pembelajaran RME. Sebelum dilakukan pengambilan sampel, maka seluruh anggota populasi diberikan pretest, selanjutnya dilakukan proses pembelajaran untuk beberapa pertemuan dan dilakukan posttest pada 
akhir pembelajaran untuk melihat hasil dari perlakuan yang telah diberikan. Rancangan desain penelitian ini digunakan untuk mengetahui apakah hasil belajar matematika siswa dengan pembelajaran menggunakan RME lebih baik bila dibandingkan dengan pembelajaran menggunakan $\mathrm{PBL}$ dan pembelajaran konvensional.

Instrumen yang dikembangkan adalah tes hasil belajar siswa sebanyak 5 soal. Sebelum soal ini digunakan pada kelas eksperimen, maka dilakukan validasi pada dua ahli pembelajaran matematika dari Universitas Pattimura. Kedua ahli pembelajaran tersebut adalah Dr. Carolina Selfisina Ayal, M.Pd dan Dr. La Moma, M.Pd. Selain itu, soal telah di uji coba pada 100 siswa kelas IX yang belajar materi SPLDV di beberapa sekolah SMP di Kota Ambon.

Setelah dilakukan proses validasi terhadap soal diperoleh hasil validasi sebesar 0.72 dan hasil uji reliabilitas sebesar 0.94. Selanjutnya pada analisis data, data yang diperoleh dianalisis dengan menggunakan aplikasi SPSS, analisis yang dilakukan yaitu statistik deskriptif, uji persyaratan data meliputi uji normalitas dan uji homogenitas, selanjutnya diuji hipotesis dengan uji-t dan ANOVA satu arah.

\section{HASIL DAN PEMBAHASAN}

Data Tabel 1 menunjukkan bahwa nilai pretest untuk ketiga kelas semuanya berada pada kualifikasi sangat rendah. Pada posttest, kualifikasi nilai untuk ketiga kelas bervariasi. Kualifikasi sangat tinggi untuk kelas RME adalah 3 siswa sedangkan untuk kelas PBL terdapat 2 siswa dan konvensional tidak ada, untuk kualifikasi tinggi terdapat 10 siswa pada kelas RME, 5 siswa pada kelas PBL dan 4 siswa pada kelas konvensional. Selanjutnya untuk kualifikasi sedang untuk kelas RME, PBL dan konvensional berturut-turut adalah 7 siswa, 9 siswa dan 6 siswa, sedangkan untuk kualifikasi rendah untuk kelas RME tidak ada, kelas PBL terdapat 4 siswa dan kelas konvensional terdapat 9 siswa. Selanjutnya untuk kualifikasi sangat rendah untuk kelas RME dan kelas PBL tidak ada, sedangkan untuk kelas konvensional terdapat 1 siswa.

Data hasil pretest dan posttest dianalisis menggunakan $N$-Gain untuk mengetahui peningkatan hasil belajar matematika dengan menggunakan model pembelajaran RME, model pembelajaran PBL dan model pembelajaran konvensional.

Tabel 1. Hasil pretest dan posttest

\begin{tabular}{cccccccc}
\hline \multirow{2}{*}{ Kualifikasi } & \multirow{2}{*}{ Nilai } & \multicolumn{3}{c}{ Pretest } & \multicolumn{3}{c}{ Posttest } \\
\cline { 3 - 8 } & & RME & PBL & PK & RME & PBL & PK \\
\hline Sangat Tinggi & $\mathrm{x}>90$ & 0 & 0 & 0 & 3 & 2 & 0 \\
Tinggi & $75<\mathrm{x} \leq 90$ & 0 & 0 & 0 & 10 & 5 & 4 \\
Sedang & $60<\mathrm{x} \leq 75$ & 0 & 0 & 0 & 7 & 9 & 6 \\
Rendah & $40<\mathrm{x} \leq 40$ & 0 & 0 & 0 & 0 & 4 & 9 \\
Sangat Rendah & $\mathrm{x}<40$ & 18 & 20 & 18 & 0 & 0 & 1 \\
\hline
\end{tabular}

Selanjutnya, untuk data pada Tabel 2 juga terlihat bahwa nilai ratarata pretest untuk kelas RME adalah 10,46 , untuk kelas PBL nilai rata-rata pretestnya adalah 7,71 dan untuk kelas konvensional nilai rata-rata pretest adalah 7,21. Selanjutnya untuk nilai rata-rata posttest untuk kelas RME adalah 79,32, untuk kelas PBL 70,40 dan kelas konvensional 61,49. 
DOI: https://doi.org/10.24127/ajpm.v10i2.3558

Tabel 2. Rata-rata nilai pretest dan posttest

\begin{tabular}{ccc}
\hline Kelas & Pretest & Posttest \\
\hline RME & 10,46 & 79.32 \\
PBL & 7,71 & 70.40 \\
Konvensional & 7,21 & 61,94 \\
\hline
\end{tabular}

\section{Uji Prasyarat Analisis}

a. Uji Normalitas

Uji prasyarat analisis meliputi uji normalitas dan homogenitas. Untuk uji normalitas data, maka dilakukan perhitungan menggunakan KolmogorovSmirnov pada nilai rata-rata $N$-Gain dan diperoleh hasil pada Tabel 3.

Tabel 3. Nilai sig normalitas rata-rata $N$-gain

\begin{tabular}{cccc}
\hline Kelas & Sig & $\boldsymbol{\alpha}$ & Ket \\
\hline RME & 0,200 & 0,05 & Terima $\mathrm{H}_{\mathrm{o}}$ \\
PBL & 0,200 & 0,05 & Terima $_{\mathrm{o}}$ \\
Konvensional & 0,200 & 0,05 & Terima $\mathrm{H}_{\mathrm{o}}$ \\
\hline
\end{tabular}

Berdasarkan pada Tabel 3 terlihat bahwa data peningkatan hasil belajar tersebut berdistribusi normal.
Setelah data yang diuji berdistribusi normal, data selanjutnya diuji homogenitas seperti pada Tabel 4.

Tabel 4. Nilai sig homogenitas rata-rata $N$-gain

\begin{tabular}{cccc}
\hline Kelas & Sig & $\boldsymbol{\alpha}$ & Ket \\
\hline Rerata $N$-Gain & 0,451 & 0,05 & Terima $\mathrm{H}_{\mathrm{o}}$ \\
\hline
\end{tabular}

Data Tabel 4, terlihat bahwa nilai ratarata $N$-Gain untuk kelas RME, PBL, dan konvensional adalah homogen. Dengan demikian analisis dengan One Way ANOVA dapat digunakan.

\section{Uji Perbedaan}

Setelah dilakukan uji prasyarat dan dinyatakan bahwa data berdistribusi normal dan homogen maka dilakukan uji perbedaan peningkatan hasil belajar matematika materi SPLDV dengan menggunakan model pembelajaran RME, PBL dan konvensional pada siswa kelas VIII SMP Negeri 15 Ambon menggunakan One Way ANOVA, diperoleh hasil seperti Tabel 5.

Tabel 5. Hasil uji one way ANOVA pengaruh model pembelajaran hasil belajar siswa

\begin{tabular}{lrrrrr}
\hline \multicolumn{7}{c}{ ANOVA } \\
\hline Nilai_GAB & \multicolumn{7}{c}{ (Sum of Squares } & df & Mean Square & \multicolumn{1}{c}{ F } & \multicolumn{1}{c}{ Sig. } \\
\hline Between Groups & 4640.203 & 2 & 2320.101 & 8.305 & .001 \\
Within Groups & 14805.987 & 53 & 279.358 & & \\
Total & 19446.190 & 55 & & & \\
\hline
\end{tabular}

Berdasarkan pada data Tabel 5, diperoleh nilai sig. dari ketiga kelas yaitu kelas dengan pembelajaran RME, PBL, dan konvensional adalah sebesar 0,01 yang berarti lebih kecil dari nilai $\alpha$ $(0,05)$, sehingga dapat disimpulkan bahwa terdapat perbedaan peningkatan hasil belajar matematika materi SPLDV dengan menggunakan model pembelajaran RME, PBL, dan konvensional. Selanjutnya, untuk mengetahui model pembelajaran yang lebih baik dari ketiga model pembelajaran tersebut, maka dilakukan pengujian lanjut dengan uji LSD. Hasil dari uji LSD dapat dilihat pada Tabel 6 yang telah disajikan. Selain itu, ditampilkan pula hasil uji perbedaan antara ketiga model pembelajaran pada Tabel 7. 
DOI: https://doi.org/10.24127/ajpm.v10i2.3558

Tabel 6. Hasil uji LSD pengaruh model pembelajaran terhadap hasil belajar

\section{Multiple Comparisons}

Dependent Variable: Nilai_GAB

LSD

\begin{tabular}{llrrr}
\hline (I) Jenis_Kelas & (J) Jenis_Kelas & Mean Difference (I-J) & Std. Error & \multicolumn{1}{c}{ Sig. } \\
\hline RME & PBL & $11.51111^{*}$ & 5.43027 & .043 \\
& KON & $22.70556^{*}$ & 5.57134 & .000 \\
PBL & RME & $-11.51111^{*}$ & 5.43027 & .043 \\
& KON & $11.19444^{*}$ & 5.43027 & .045 \\
KON & RME & $-22.70556^{*}$ & 5.57134 & .000 \\
& PBL & $-11.19444^{*}$ & 5.43027 & .045 \\
\hline
\end{tabular}

*. The mean difference is significant at the 0.05 level.

Tabel 7. Hasil uji perbedaan dengan menggunakan one way ANOVA

\begin{tabular}{cccc}
\hline Kelas & Sig & $\boldsymbol{\alpha}$ & Ket \\
\hline RME dan PK & 0,000 & 0,05 & Terima $\mathrm{H}_{1}$ \\
RME dan PBL & 0,043 & 0,05 & Terima $\mathrm{H}_{1}$ \\
PBL dan PK & 0,045 & 0,05 & Terima $\mathrm{H}_{1}$ \\
\hline
\end{tabular}

Berdasarkan data pada Tabel 6, dapat disimpulkan bahwa 1) Perbedaan peningkatan hasil belajar matematika materi SPLDV dengan menggunakan model pembelajaran RME dan model pembelajaran konvensional pada siswa kelas VIII SMP Negeri 15 Ambon. 2) Perbedaan peningkatan hasil belajar matematika materi SPLDV dengan menggunakan model pembelajaran RME dan model pembelajaran PBL pada siswa kelas VIII SMP Negeri 15 Ambon. 3) Perbedaan peningkatan hasil belajar matematika materi SPLDV dengan menggunakan model pembelajaran PBL dan model pembelajaran konvensional pada siswa kelas VIII SMP Negeri 15 Ambon. 4) Perbedaan peningkatan hasil belajar matematika materi SPLDV dengan menggunakan model pembelajaran RME, model pembelajaran PBL dan model pembelajaran konvensional pada siswa kelas VIII SMP Negeri 15 Ambon.

Berdasarkan pada deskripsi hasil yang telah dibahas sebelumnya. Terlihat bahwa memang terdapat peningkatan hasil belajar pada siswa kelas VIII SMP Negeri 15 Ambon pada materi SPLDV dengan menggunakan model pembelajaran RME, PBL, dan konvensional.

\section{RME dan Konvensional}

Berdasarkan pada hasil uji statistik, hasil belajar siswa mengalami peningkatan hal ini terlihat pada nilai rata-rata $N$-Gain untuk kelas RME sebesar 0,7725 yang masuk kategori tinggi, sedangkan untuk kelas konvensional nilai rata-rata $N$-Gainnya adalah 0,5910 dengan kategori sedang. Nilai rata-rata pretest untuk kelas RME dan konvensional berturut-turut adalah 10,46 dan 7,21 dan setelah diberi perlakuan nilai rata-rata posttest kelas RME dan konvensional berturut-turut menjadi 79,32 dan 61,93.

Menurut penelitian (Widjaja \& Heck, 2003) dijelaskan bahwa, kelas eksperimen dengan menggunakan model pembelajaran RME mengalami kemajuan prestasi belajar. Hal ini dikarenakan siswa akan belajar dari kondisi realistik. Pembelajaran Matematika Realistik (PMR) di sekolah dilaksanakan dengan menempatkan realitas dan lingkungan siswa sebagai titik awal pembelajaran. Masalahmasalah yang nyata atau dapat 
dibayangkan dengan baik oleh siswa dan digunakan sebagai sumber munculnya konsep atau pengertianpengertian matematika yang semakin meningkat. Jadi pembelajaran tidak dimulai dari definisi, teorema atau sifatsifat dan selanjutnya diikuti dengan contoh-contoh, namun sifat, definisi, teorema itu diharapkan "seolah-olah ditemukan kembali" oleh siswa.

Berdasarkan pada hasil analisis statistik serta penjelasan tersebut, dapat disimpulkan bahwa peningkatan hasil belajar matematika materi SPLDV dengan menggunakan model pembelajaran RME lebih tinggi dari model pembelajaran konvensional pada siswa kelas VIII SMP Negeri 15 Ambon.

\section{RME dan PBL}

Hasil belajar siswa mengalami peningkatan, hal ini terlihat pada nilai rata-rata $N$-Gain untuk kelas RME sebesar 0,7725 yang masuk kategori tinggi, sedangkan untuk kelas konvensional nilai rata-rata $N$-Gainnya adalah 0,6806 dengan kategori sedang. Nilai rata-rata pretest untuk kelas RME dan konvensional berturut-turut adalah 10,46 dan 7,71 dan setelah diberi perlakuan nilai rata-rata posttest kelas RME dan kelas PBL berturut-turut menjadi 79,32 dan 70,39. Selanjutnya data peningkataan Hasil belajar matematika untuk tiga model pembelajaran berberbeda dapat ditunjukan pada Tabel 8 , sedangkan data dari nilai rataan $\mathrm{N}$-Gain dapat dilihat pada Tabel 9.

Tabel 8. Data peningkatan hasil belajar matematika

\begin{tabular}{cccccccccccc}
\hline & \multicolumn{3}{c}{ Kelas RME } & \multicolumn{4}{c}{ Kelas PBL } & \multicolumn{4}{c}{ Kelas Konvensional } \\
\hline $\boldsymbol{x}_{\text {min }}$ & $\boldsymbol{x}_{\text {maks }}$ & $\bar{x}$ & $\boldsymbol{s}$ & $\boldsymbol{x}_{\text {min }}$ & $\boldsymbol{x}_{\text {maks }}$ & $\bar{x}$ & $\boldsymbol{s}$ & $\boldsymbol{x}_{\text {min }}$ & $\boldsymbol{x}_{\text {maks }}$ & $\bar{x}$ & $\boldsymbol{s}$ \\
\hline 0,62 & 0,93 & 0,7725 & 0,9 & 0,51 & 0,93 & 0,6806 & 0,13 & 0,32 & 0,79 & 0,5910 & 0,12 \\
\hline
\end{tabular}

Tabel 7. Nilai Rataan $N$-Gain dan Kategorinya

\begin{tabular}{ccc}
\hline Kelas & $\begin{array}{c}\text { Nilai Rataan } \\
\boldsymbol{N} \text {-Gain }\end{array}$ & Kategori \\
\hline Kelas RME & 0,7725 & Tinggi \\
Kelas PBL & 0,6806 & Sedang \\
Kelas PK & 0,5910 & Sedang \\
\hline
\end{tabular}

Data Tabel 6 dan 7, terlihat bahwa peningkatan hasil belajar untuk kelas RME terdapat peningkatan dengan ratarata $N$-Gain sebesar 0,7725 termasuk dalam kategori tinggi. Sedangkan untuk kelas PBL terdapat peningkatan dengan rata-rata $N$-Gain sebesar 0,6806 termasuk dalam kategori sedang, dan untuk kelas konvensional terdapat peningkatan dengan rata-rata $\mathrm{N}$-Gain sebesar 0,5910 termasuk dalam kategori sedang.
Adapun pembahasan dari hasil yang telah diperoleh tentang perbandingan ketiga jenis model pembelajaran, yaitu sebagai berikut:

1) Perbandingan RME dan PBL Peningkatan hasil belajar matematika materi SPLDV dengan model pembelajaran RME lebih tinggi dari hasil belajar dengan model pembelajaran PBL. Hal ini terlihat dari nilai rata-rata $N$-Gain kelas RME lebih besar dari nilai rata-rata $N$-Gain kelas PBL yaitu 0,7725 > 0,6806.

Nilai rata-rata $N$-Gain kelas RME dan kelas PBL dapat disimpulkan bahwa terdapat peningkatan hasil belajar untuk kedua kelas tersebut, namun peningkatan hasil belajar kelas RME lebih tinggi dari PBL. Hal ini terlihat pada nilai rata-rata $\mathrm{N}$-Gain RME yaitu $0,7725>$ nilai rata-rata $N$ - 
Gain PBL yaitu 0,6806. Ini menunjukan bahwa kedua model tersebut mengalami peningkatan hasil belajar.

Pada pembelajaran RME siswa ditantang untuk aktif bekerja bahkan diharapkan agar dapat mengkonstruksi atau membangun sendiri pengetahuan yang akan diperolehnya. Jelas bahwa dengan menggunakan model pembelajaran RME siswa akan ditantang untuk aktif serta dapat mengkonstruksi pengetahuan, sehingga siswa akan lebih mudah untuk memahami materi dikarenakan siswa yang mengkonstruksi pengetahuan itu sendiri.

Selain itu PBL merupakan inovasi dalam pembelajaran karena dalam PBL kemampuan berpikir siswa betul-betul dioptimalisasikan melalui proses kerja kelompok atau tim yang sistematis, sehingga siswa dapat memberdayakan, mengasah, menguji, dan mengembangkan kemampuan berpikir secara berkesinambungan (Dahl, 2018). Kemampuan pemecahan masalah matematika siswa yang diajarkan dengan pembelajaran RME lebih baik dari pada kemampuan pemecahan masalah matematika siswa yang diajarkan dengan pembelajaran PBL (Hairunisah et al., 2020). Berdasarkan pada penjelasan di atas dapat disimpulkan bahwa terdapat peningkatan hasil belajar matematika dengan menggunakan model pembelajaran RME dan model pembelajaran PBL, selain itu peningkatan hasil belajar matematika dengan menggunakan model pembelajaran RME lebih tinggi dari model pembelajaran PBL.

2) Perbandingan RME dan Konvensional Peningkatan hasil belajar matematika materi SPLDV dengan menggunakan model pembelajaran
RME lebih tinggi dari model pembelajaran konvensional. Hal ini terlihat dari nilai rata-rata $N$-Gain kelas RME > nilai rata-rata $N$-Gain kelas konvensional yaitu $0,7725>0,5910$.

Peningkatan Hasil Belajar Matematika dengan Menggunakan Model PBL Lebih Tinggi dari Model Pembelajaran Konvensional. Hasil uji statistik, hasil belajar siswa mengalami peningkatan hal ini terlihat pada nilai rata-rata $N$-Gain untuk kelas PBL sebesar 0,6806 yang masuk kategori sedang, untuk kelas konvensional nilai rata-rata $N$-Gainnya adalah 0,5910 dengan kategori sedang. Nilai rata-rata pretest untuk kelas PBL dan konvensional berturut-turut adalah 7,71 dan 7,21 dan setelah diberi perlakuan nilai rata-rata posttest kelas PBL dan konvensional berturut-turut menjadi 70,39 dan 61,93. Dari nilai rata-rata $N$ Gain kelas PBL dan konvensional dapat disimpulkan bahwa terdapat peningkatan hasil belajar untuk kedua kelas tersebut, namun peningkatan hasil belajar kelas PBL lebih tinggi dari kelas konvensional. Hal ini terlihat pada nilai rata-rata $N$-Gain kelas PBL yaitu 0,6806 $>$ nilai rata-rata $N$-Gain kelas konvensional yaitu 0,5920 .

PBL adalah model pembelajaran yang dapat membentuk dan memajukan siswa supaya mempunyai keahlian dalam menyelesaikan suatu permasalahan dalam kegiatan belajar siswa dan juga untuk mendorong siswa mengembangkan keterampilan berfikir agar dapat berfikir lebih kritis. Hal ini jelas menjelaskan bahwa dengan menggunakan model pembelajaran PBL siswa akan diperhadapkan dengan masalah dan siswa akan dituntut untuk berfikir secara kritis untuk menyelesaikan masalah tersebut, sehingga siswa akan lebih memahami 
cara untuk menyelesaikan masalah tersebut (J R Batlolona et al., 2020).

Berdasarkan pada penjelasan sebelumnya dapat disimpulkan bahwa terdapat peningkatan hasil belajar matematika dengan menggunakan model pembelajaran PBL dan model pembelajaran konvensional, selain itu peningkatan hasil belajar matematika dengan menggunakan model pembelajaran PBL lebih tinggi dari model pembelajaran konvensional.

\section{3) Perbandingan PBL dan Konvensional} Peningkatan hasil belajar matematika dengan menggunakan model pembelajaran PBL lebih tinggi dari model pembelajaran konvensional. Hal ini terlihat dari nilai rata-rata $N$ Gain kelas PBL > nilai rata-rata $N$-Gain kelas konvensional yaitu $0,6806>$ 0,5910. 4) Peningkatan hasil belajar matematika dengan menggunakan model pembelajaran RME lebih tinggi dari model pembelajaran PBL dan model pembelajaran konvensional.

\section{4) Perbandingan RME, PBL, dan Konvensional \\ Peningkatan hasil belajar} matematika dengan menggunakan model pembelajaran RME lebih tinggi dari model pembelajaran PBL dan model pembelajaran konvensional. Hasil studi sebelumnya menyampaikan bahwa PBL lebih berpengaruh dalam meningkatkan hasil belajar matematika siswa. Hal ini terlihat pada hasil belajar matematik dengan PBL sebesar 80.25 sedangkan dengan RME siswa hanya mampu mencapai nila matematik sebesar 78.44 (Kempa et al., 2019). Pada pembelajaran dengan PBL guru menggunakan media interaktif dalam mendukung pembelajaran matematika bila bandingkan dengan pembelajaran RME yang cenderung lebih konvesional. Terakit hasil penelitian bahwa RME dalam topik SPLDV lebih tinggi bila dibandingkan dengan kela PBL dan konvesional. Hal ini karena RME mengaplikasikan hal-hal yang kontekstual yang terjadi dalam kehidupan sehari-hari.

Berpedoman pada hasil uji statistik, dengan nilai rata-rata $N$-Gain kelas RME, PBL dan konvensional secara berturut-turut $0,7725,0,6806$ dan 0,5920 dapat disimpulkan bahwa peningkatan hasil belajar matematika materi SPLDV dengan menggunakan model pembelajaran RME lebih baik dari model PBL dan model pembelajaran konvensional. Hal ini dikarenakan nilai rata-rata $N$-Gain kelas RME $0,7725>$ nilai rata-rata $N$-Gain kelas PBL 0,6806 dan rata-rata $N$-Gain kelas konvensional 0,5920.

5) Perbedaan Peningkatan Hasil Belajar (RME, PBL, dan Konvensional)

Dari hasil uji prasyarat, data kelas RME, kelas PBL dan kelas konvensional berdistribusi normal dan ketiga-tiganya homogen. Setelah diuji perbedaan peningkatan menggunakan uji One Way ANOVA diperoleh nilai Sig untuk kelas RME dan kelas konvensional yaitu 0,000. Nilai Sig ini < nilai $\alpha \quad(0,05)$ sehingga dapat disimpulkan bahwa terdapat perbedaan peningkatan hasil belajar matematika dengan menggunakan model pembelajaran RME dan model pembelajaran konvensional

Selanjutnya untuk kelas RME dan kelas PBL, nilai sig yaitu $0,043<$ nilai $\alpha$ $(0,05)$. Dari data di atas dapat disimpulkan bahwa terdapat perbedaan peningkatan hasil belajar matematika dengan menggunakan model pembelajaran RME dan model pembelajaran PBL. 
DOI: https://doi.org/10.24127/ajpm.v10i2.3558

Kelas PBL dan kelas konvensional nilai Sig yaitu $0,045<$ nilai $\alpha \quad(0,05)$. Hal ini dapat disimpulkan bahwa terdapat perbedaan peningkatan hasil belajar matematika dengan menggunakan model pembelajaran PBL dan model pembelajaran konvensional.

Berdasarkan pada pembahasan di atas bahwa terdapat perbedaan peningkatan hasil belajar matematika materi SPLDV dengan menggunakan model pembelajaran RME, model pembelajaran PBL dan model konvensional pada siswa kelas VIII SMP Negeri 15 Ambon. Kelebihan dari penelitian ini adalah memberikan dampak postif dalam meningkatkan hasil belajar siswa pada topik SPLDV sehingga mempertajam kemampuan matematik siswa untuk menyelesaikan soal-soal konstekstual, sehingga apa yang dipelajari peserta didik menjadi their own knowledge. Penelitian ini menunjukkan bahwa melalui aktivitas RME berbasis kontekstual dalam setiap fase pembelajaran, siswa dapat menemukan konsep. Siswa dapat mengembangkan kemampuannya dalam menemukan konsep yang dimulai dari menggunakan pengetahuan informal sehingga memperoleh pengetahuan formal di akhir pembelajaran. Hal ini mengakibatkan siswa tidak menghafal konsep atau rumus, namun mengalami proses menemukan konsep sehingga pembelajaran lebih bermakna dan kemampuan peserta didik lebih meningkat. Sejalan dengan pendapat Suciana et al., (2020) bahwa RME didik meningkatkan hasil belajar siswa dan memberikan kontribusi besar dalam pengembangan kemampuan berpikir matematis siswa.

Secara keseluruhan RME mampu memberikan efek potensial dalam pengembangan kemampuan literasi matematika siswa dari kemampuan kognitif rendah ke tinggi. Hasil ini sejalan dengan hasil penelitian (Heriyadi \& Prahmana, 2020) yang menyatakan bahwa pembelajaran yang mengadopsi kelima karakteristik RME telah mampu menumbuhkan kemampuan literasi matematis siswa dan hasil penelitian ini, menambah bukti otentik bahwa implementasi RME dalam pembelajaran dapat berpotensi untuk meningkatkan kemampuan literasi matematis siswa. Selain itu, hasil ini juga memberikan kontribusi postif bagi guru dalam upaya menyediakan pembelajaran yang bermutu yang menghubungkan materi materi dengan pengalaman sehari-hari.

\section{KESIMPULAN DAN SARAN}

Berdasarkan hasil temuan dan pembahasan terdapat perbedaan hasil belajar siswa yang dibelajarkan dengan RME, PBL dan Konvensioal. Dari ketiga model yang dipakai terbukti bahwa RME lebih unggul bila dibandingkan dengan PBL dan konvensional Terdapat perbedaan peningkatan hasil belajar matematika materi SPLDV dengan menggunakan model pembelajaran RME, model PBL dan model pembelajaran konvensional. Dengan demikian RME direkomendasikan dalam meningkatkan hasil belajar matematika siswa. Manfaat dari penelitian ini adalah guru dapat memilih metode yang tepat salah satunya adalah RME dalam meningkatkan kemampuan siswa pada materi yang lain pada jenjang sekolah manengah atau pendidikan tinggi.

Keterbatasan dari penelitian ini adalah hanya mengekplorasi hasil belajar siswa kelas VIII tingkat Sekolah Menengah Pertama. Diharapkan penelitian untuk mengetahui model pembelajaran RME dan model 
pembelajaran PBL dalam meningkatkan hasil belajar matematika pada topik yang dan variabel yang berbeda misalnya gaya belajar, kecerdasan emosial dan inovasi siswa.

\section{DAFTAR PUSTAKA}

Batlolona, J R, Singerin, S., \& Diantoro, M. (2020). Influence of Problem Based Learning Model on Student Mental Models. 16(June), 14-23. https://doi.org/10.15294/jpfi.v16i1 .14253

Batlolona, John Rafafy, Diantoro, M., Wartono, \& Leasa, M. (2020). Students' mental models of solid elasticity: Mixed method study. Journal of Turkish Science Education, 17(2), 200-210. https://doi.org/10.36681/tused.202 0.21

Dahl, B. (2018). What is the problem in problem-based learning in higher education mathematics. European Journal of Engineering Education, 43(1), 112-125. https://doi.org/10.1080/03043797. 2017.1320354

Eronen, L., \& Kärnä, E. (2018). Students Acquiring Expertise through Student-Centered Learning in Mathematics Lessons. Scandinavian Journal of Educational Research, 62(5), 682-700. https://doi.org/10.1080/00313831. 2017.1306797

Hairunisah, H., Mulyono, M., \& ... (2020). Mathematical Literacy Ability Reviewed from Cognitive Style of Students on Mind mapping Learning Model with Constructivism Approach. Unnes Journal of ..., 8(1), 57-64. https://journal.unnes.ac.id/sju/inde x.php/ujmer/article/view/30452
Harahap, K. A., \& Surya, E. (2017). Application of Cooperative Learning Model With Type of Two Stay Two Stray to Improve Results of Mathematics Teaching. International Journal of Sciences: Basic and Applied Research (IJSBAR), 33(2), 156-165.

Heriyadi, H., \& Prahmana, R. C. I. (2020). Pengembangan Lembar Kegiatan Siswa Menggunakan Pendekatan Pendidikan Matematika Realistik. AKSIOMA: Jurnal Program Studi Pendidikan Matematika, 9(2), 395-412. https://doi.org/10.24127/ajpm.v9i 2.2782

Kempa, R., Laurens, T., Leasa, M., Rafafy Batlolona, J., Batlolona, M., \& Julian Enriquez, J. (2019). Comparison of Problem Based Learning and Realistic Mathematics Education to Improve Students Academic Performance. Jurnal Pendidikan Progresif, November. https://doi.org/10.23960/jpp.v9.i2. 201905

King, D., Varsavsky, C., Belward, S., \& Matthews, K. (2017). Investigating students' perceptions of graduate learning outcomes in mathematics. International Journal of Mathematical Education in Science and Technology, 48(S1), S67-S80.

https://doi.org/10.1080/0020739X .2017 .1352044

Kolovou, M., \& Kim, N. J. (2020). Effects of implementing an integrative drama-inquiry learning model in a science classroom. Journal of Educational Research, 113(3), 191-203. https://doi.org/10.1080/00220671. 2020.1771673 
Laurens, T., Batlolona, F. A., Batlolona, J. R., \& Leasa, M. (2018). How does realistic mathematics education (RME) improve students' mathematics cognitive achievement? Eurasia Journal of Mathematics, Science and Technology Education, 14(2). https://doi.org/10.12973/ejmste/76 959

Li, X., Xie, F., Li, X., Li, G., Chen, X., Lv, J., \& Peng, C. (2020). Development, application, and evaluation of a problem-based learning method in clinical laboratory education. Clinica Chimica Acta, 510(July), 681684.

https://doi.org/10.1016/j.cca.2020. 08.037

Mbacho, N. W., \& Changeiywo, J. M. (2013). Effects of Jigsaw Cooperative Learning Strategy on Students' Achievement by Gender Differences in Secondary School Mathematics in Laikipia East District, Kenya. Journal of Education and Practice, 4(16), 55-63.

Perusso, A., \& Baaken, T. (2020). Assessing the authenticity of cases, internships and problembased learning as managerial learning experiences: Concepts, methods and lessons for practice. International Journal of Management Education, 18(3), 100425.

https://doi.org/10.1016/j.ijme.202 0.100425

Ratumanan, G. T. (2016). Motivasi siswa dalam pembelajaran matematika. Di sampaikan dalam seminar nasional pendidikan matematika 2016 pengembangan penelitian pendidikan matematika untuk mendukung peningkatan kualitas pembelajaran matematika [Student motivation in learning mathematics. Delivered in the 2016 national mathematics education seminar development of mathematics education research to support the improvement of the quality of mathematics learning]. Hal 6-13

Revina, S., \& Leung, F. K. S. (2019). Issues involved in the adoption of Realistic Mathematics Education in Indonesian culture. Compare, 00(00), $1-20$. https://doi.org/10.1080/03057925. 2019.1650636

Rylands, L. J., \& Shearman, D. (2018). Mathematics learning support and engagement in first year engineering. International Journal of Mathematical Education in Science and Technology, 49(8), 1133-1147.

https://doi.org/10.1080/0020739X .2018 .1447699

Seibert, S. A. (2021). Problem-based learning: A strategy to foster generation Z's critical thinking and perseverance. Teaching and Learning in Nursing, 16(1), 8588.

https://doi.org/10.1016/j.teln.2020 .09 .002

Shin, S., Rachmatullah, A., Roshayanti, F., Ha, M., \& Lee, J. K. (2018). Career motivation of secondary students in STEM: a crosscultural study between Korea and Indonesia. International Journal for Educational and Vocational Guidance, 18(2), 203-231. https://doi.org/10.1007/s10775017-9355-0

Sitorus, J., \& Masrayati. (2016). Students' creative thinking process stages: Implementation of realistic mathematics education. 
DOI: https://doi.org/10.24127/ajpm.v10i2.3558

Thinking Skills and Creativity, 22, 111-120. https://doi.org/10.1016/j.tsc.2016. 09.007

Suciana, F., Musdi, E., \& Arnawa, I. M. (2020). Pengembangan Alur Belajar Berbasisrealistic Mathematic Education (Rme) Pada Materi Lingkaran. AKSIOMA: Jurnal Program Studi Pendidikan Matematika, 9(2), 369-377.

https://doi.org/10.24127/ajpm.v9i 2.2769

Sumirattana, S., Makanong, A., \& Thipkong, S. (2017). Using realistic mathematics education and the DAPIC problem-solving process to enhance secondary school students' mathematical literacy. Kasetsart Journal of Social Sciences, 38(3), 307-315. https://doi.org/10.1016/j.kjss.2016 .06 .001

Widjaja, Y. B., \& Heck, A. (2003). How a realistis mathematics education approach and microcomputer-based laboratory worked in Lessons on graphing at an Indonesian Junior high school. Journal of Science and Mathematics Education in South East Asia, 26(2), 1-51.

Wu, T., Shen, H., Sheng, Y., Zhao, F., Guo, N., Liao, L., Li, L., Li, Y., \& Dong, X. (2020). Use of cognitive correction training improves learning for children with mathematics learning disability. Applied Neuropsychology: Child, 9(2), 172-178. https://doi.org/10.1080/21622965. 2018.1552866

Yew, E. H. J., \& Goh, K. (2016). Problem-Based Learning: An Overview of its Process and Impact on Learning. Health
Professions Education, 2(2), 7579.

https://doi.org/10.1016/j.hpe.2016 .01 .004

Zwart, D. P., Van Luit, J. E. H., Noroozi, O., \& Goei, S. L. (2017). The effects of digital learning material on students' mathematics learning in vocational education. Cogent Education, 4(1), 1-10. https://doi.org/10.1080/2331186X .2017 .1313581 